\title{
Sustainability in Ultra Precision and Micro Machining: A Review
}

\author{
Frank Schneider ${ }^{1} \cdot$ Jayanti Das $^{2} \cdot$ Benjamin Kirsch $^{1} \cdot$ Barbara Linke $^{2} \cdot$ Jan C. Aurich $^{1}$
}

Received: 10 May 2017 / Revised: 6 December 2017 / Accepted: 26 December 2017 / Published online: 8 February 2019

(c) The Author(s) 2019

\begin{abstract}
Ultra precision and micro machining processes become more and more important. This can be led back to the development of functionalized surfaces and parts and the mass production of smaller products e.g. lenses for personal devices. With increasing application and distribution, the importance of sustainability in these processes also increases. In this paper, an overview of ultra precision and micro machining in a system approach is given and the most decisive input parameters are elaborated. Included are general findings and current issues of process design with regard to the economic, environmental and social dimension of sustainability. Finally, it is discussed how the sustainability of ultra precision and micro machining can be increased and for which class of products certain strategies are recommended.
\end{abstract}

Keywords Sustainability $\cdot$ Ultra precision machining $\cdot$ Micro machining

\section{Introduction}

Manufacturing technologies offer plenty of opportunities to improve sustainability by reducing environmental impact or by the more efficient use of resources. Possible improvements in sustainability are related to processes, machines or the overall system. To realize the idea of green manufacturing, all production technologies have to be examined with respect to their possible contribution to improved sustainability [1,2].

Sustainability is achieved when the actual consumption rate matches the sustainable rate. Life Cycle Assessment helps to investigate the potential for improvement in order to bridge the gap between today's consumption rates and the needed consumption rate to reach a sustainable state (see Fig. 1).

Dornfeld et al. [3] postulated the concept of "technology wedges" that reduce the current consumption rate stepwise aiming at the fulfillment of the sustainability requirements.

Benjamin Kirsch

benjamin.kirsch@mv.uni-kl.de

1 Institute for Manufacturing Technology and Production Systems (FBK), University of Kaiserslautern, Green Building 301-1205, 67663 Kaiserslautern, RLP, Germany

2 Mechanical and Aerospace Engineering, University of California, Davis, One Shields Avenue, Davis, CA 95616, USA
This approach relies on the basic idea that the sum of many small changes or improvements is equivalent to a major change.

Ultra precision and micro manufacturing are playing a significant role in advanced manufacturing technology. The applications of ultra precision cutting and micro machining are increasing in the last decades and keep fueling market economy [3]. Ultra precision processes allow to achieve surface roughness down to the nanometer scale [4] and are applied for example to manufacture optical components. Micro machining processes on the other hand are adequate technologies to manufacture micro components, micro features, and micro structures [5].

To the best knowledge of the authors, no comprehensive overview of the sustainability aspects of ultra precision and micro machining has been published. For example Yoon et al. [6] only considered conventional machining processes in their review. The aim of this work is therefore to provide this overview. First, the necessary terminology is defined, followed by an inventory analysis in connection with the explanation of the most relevant factors of sustainability. Finally, possible approaches to improve sustainability are presented. 


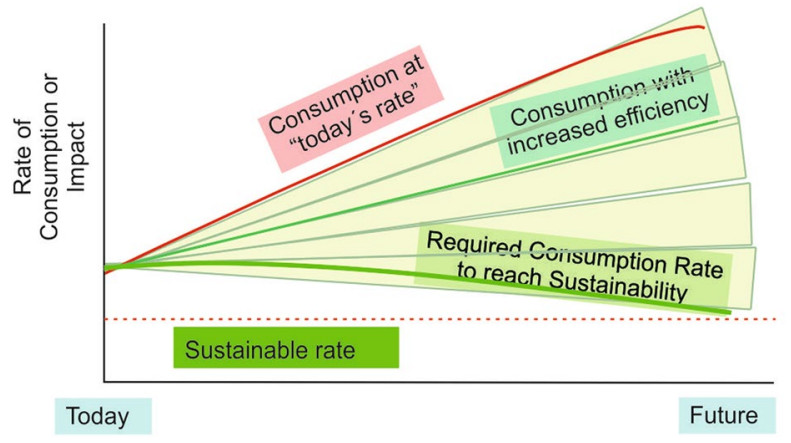

Fig. 1 Concept of "technology wedges" [1]

\section{Fundamentals}

\subsection{Ultra Precision and Micro Machining}

Definitions for ultra precision machining and micro machining processes are provided by Mativenga [7] and Brinksmeier [8] in the CIRP Encyclopedia of Production Engineering. Mativenga [7] defined micro machining as “(...) a manufacturing technology that involves the use of mechanical micro tools with geometrically defined cutting edges in the subtractive fabrication of devices or features with at least some of their dimensions in the micrometer range $(1-999 \mu \mathrm{m})$ ".

Brinksmeier [7] defined ultra precision machining as " (...) a machining process whose accuracy has been driven to its ultimate technological limits, irrespective of the nature of the process and the size of the workpiece (macro-, micro-, or nanoscopic)."

A delineation of these processes in relation to conventional machining according to Brinksmeier [9], which considers both component size and accuracy is illustrated in Fig. 2.

Ultra precision manufacturing is a dynamic field of research whose application possibilities are already enormous and yet more to explore. The broader area of application for ultra precision manufacturing (UPM) covers machining of semiconductor and optical parts with high dimensional accuracy. Furthermore, UPM is increasingly applied in the field of consumer products such as portable electronic devices or automotive fuel-injection devices under high accuracy and tight tolerances. Sophisticated optical parts with high surface finish are for example: optical glancing mirrors for X-ray telescopes, elliptical cylinder mirrors for synchrotron orbital radiation, and electroplated copper memory disks for computers widely used for commercial and industrial applications [10]. Another challenge and opportunity for ultra precision manufacturing lies in manufacturability of new materials.

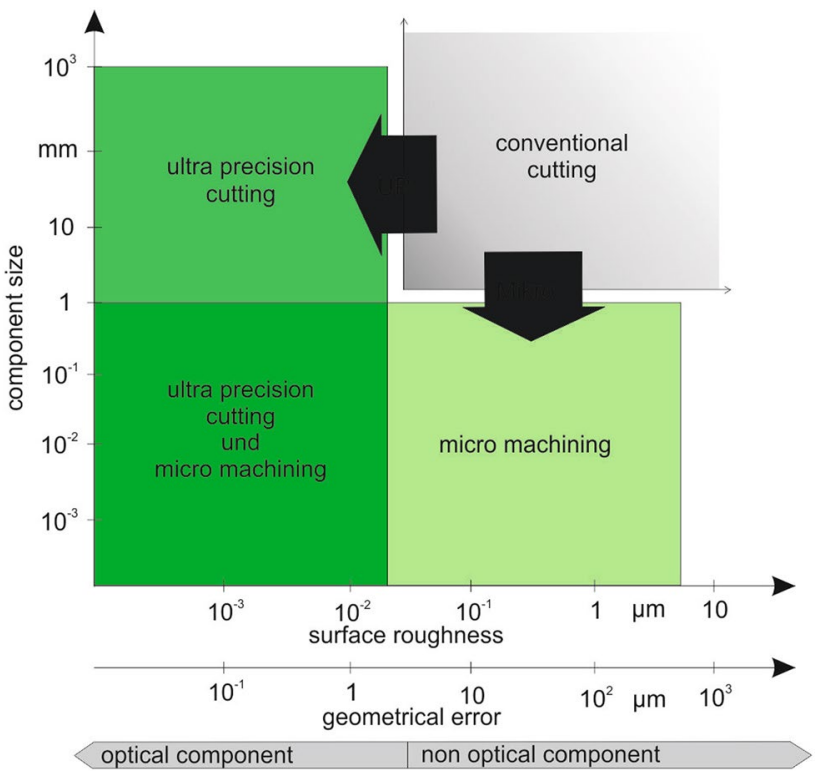

Fig. 2 Component size and accuracy in micro machining and ultra precision cutting [9]

For example, composite materials have been increasingly used in aerospace industry, satellite bearing, inertia navigation systems, and laser reflectors [11]. Ultra precision manufacturing not only lowers the cost of optical parts themselves but also for mold cavities of mass production lenses. For example, the production cost of contact lenses both soft and hard can be reduced by manufacturing mold cavities in an ultra precision machining process compared to polishing processes [12].

\subsection{Size Effects}

The findings of conventional machining processes cannot simply be scaled down to the dimensions of ultra precision and micro machining. For those, aspects like roundness errors or spindle eccentricities become much more dominant than for the conventional processes. Non scalable effects are commonly referred to as size effects. Vollertsen [13] defined size effects as "(...) deviations from intensive or proportional extrapolated extensive values of process characteristics which occur, when scaling the geometrical dimensions".

Size effects can be classified in three categories. The classification of size effects is based on the considered property, which is responsible for the existing effects and held constant. The three categories are density, shape and micro structure size effects [13].

An example of density effects are defects contained in the material. Considering conventional workpieces sizes, the number of defects in different workpieces is large so that the mechanical properties are not influenced and deemed to be constant. For very small workpiece sizes on the other hand, 
the mechanical properties of different workpieces can vary due to few defects. Shape effects result from the fact that certain properties are hinged on the volume or the size of the surface. For example, while the surface of a spherical workpiece is proportional to the square of the radius, the volume is proportional to the cube of the radius. A size effect hence occurs when the regarded property depends on surface and volume. The last category of size effects is based on the fact that it is technologically impossible to scale all micro structural values at the same time in the same magnitude [13].

\subsection{Life Cycle Assessment}

A method to assess the environmental impact of products, services or systems on the environment is the life cycle assessment (LCA) standardized by the International Organization of Standardization (ISO) in standard ISO1404ff [14]. LCA considers the whole life cycle of products from the extraction of raw natural resources right up to the product recycling process or final disposal.

Regarding the impacts on the environment, various factors are considered such as emissions (e.g. their effect on climate change), physical interventions (e.g. use of water) and the use and consumption of abiotic and biotic resources. The first phase is the goal and scope definition and includes the determination of the aims of the LCA as well as its extent including the system boundaries, the modelling framework and the environmental impact that will be considered. Furthermore, a functional unit (e.g. surface roughness) is defined to characterize the system quantitatively [14].
The following phase is the inventory analysis and includes the identification of all sub-processes of the defined systems. The inventory of the identified processes is analyzed in a flow model regarding the scope definition such as the input of resources or energy and the output of the product, e.g. emissions or waste [14].

In the impact assessment, the results of the inventory analysis are ascribed to the environmental impacts defined in phase 1 . This quantitative ascription allows to assess the influence of the single impacts. The European Commission recommends three areas of protection: human health, natural environment, and natural resources [15]. Inventory results to describe these areas in a physical way are for example climate change potential or resource depletion. In the final phase, the results of the three other phases of the LCA are interpreted and evaluated with respect of the defined goal of the LCA [14].

\section{Sustainability Aspects in Ultra Precision and Micro Machining}

A suitable way to study the sustainability of manufacturing processes is the life cycle inventory analysis [16]. Based on the procedure proposed by Linke [16] to investigate grinding, input and output quantities of ultra precision and micro machining are identified (Fig. 3). The most important influences in terms of sustainability from the perspective of the authors are considered in more detail.

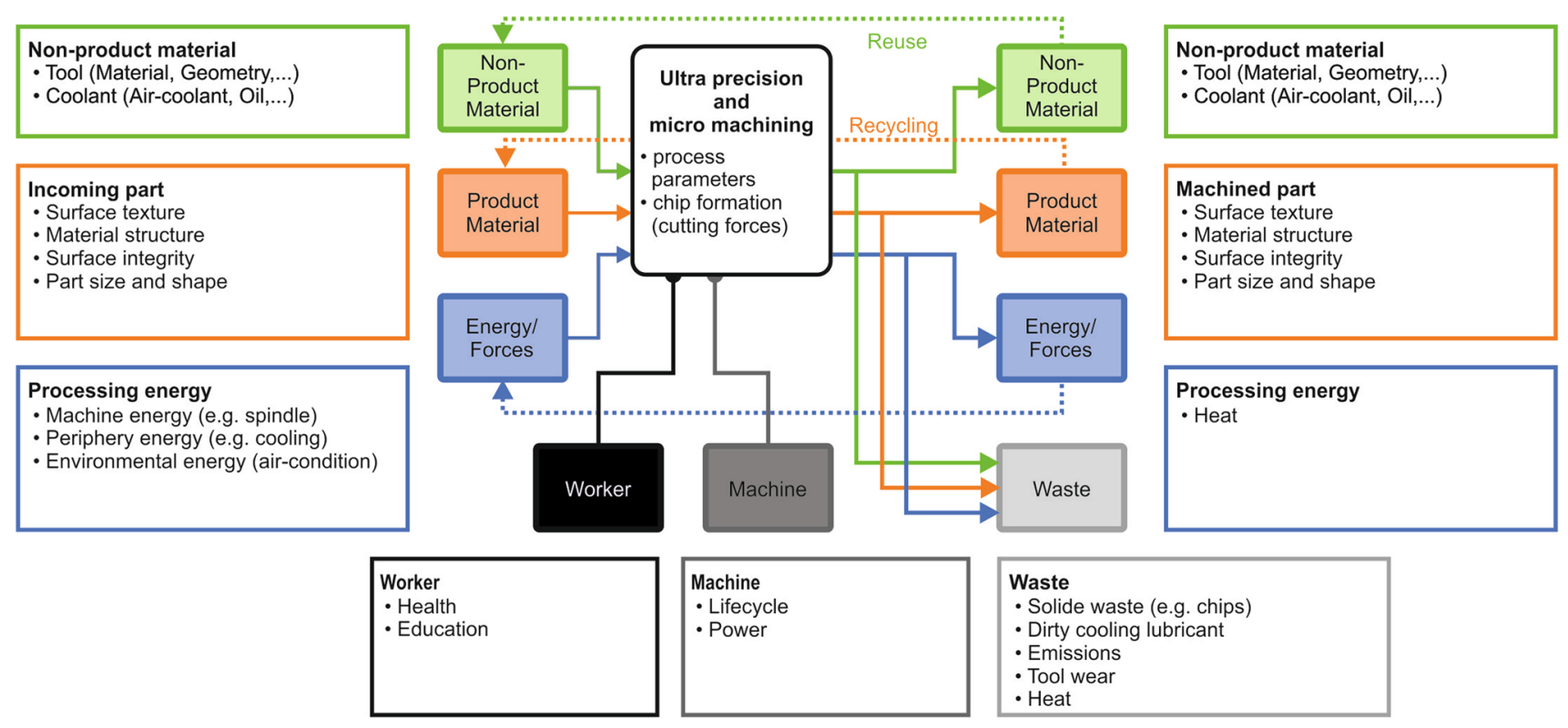

Fig. 3 In- and output diagram of ultra precision and micro machining 


\subsection{Machine Tools}

Machine tools have a high impact on the sustainability of machining processes. Common ultra precision machine tools have relatively large dimensions compared to the workpiece dimensions. A current research goal is to better align the machine tool size with the workpiece size (square foot manufacturing). In addition to reducing the consumption of resources, machine mass could be reduced and a higher machine dynamic, i.e. faster axes movements, could be realized [17]. Furthermore, it is necessary to adapt the machine tool components to the requirements of square foot manufacturing. The concept of square foot manufacturing allows to reduce the machine costs, the energy consumption and the use of resources. An example is the manufacturing of small high-frequency tool spindles for micro cutting processes by Aurich et al. [18].

\subsection{Chip Formation and Process Forces}

Both ultra precision machining and micro machining are characterized by very small undeformed chip thicknesses in relation to the cutting edge radii applied [5]. In other words, the cutting edge cannot be regarded as sharp. The resulting low ratio of undeformed chip thickness to cutting edge radius has a significant influence on the chip formation process, and thus on friction and cutting forces occurring during machining. Results of Lucca [19] and Moriwaki [20] show that in these conditions the resulting specific cutting force can no longer be described with models of conventional machining as with for example the cutting model by Merchant [21] (Fig. 4a). To describe the influence of the relationship of cutting edge radius to undeformed chip thickness, special models such as the model of the rounded cutting edge from Kim [22] were developed.

Balogun and Mativenga [23] investigated the influence of undeformed chip thickness on the specific energy. The results show that with very small undeformed chip thickness the specific energy increases exponentially.

The varying effective rake angle (Fig. 4b) along the cutting edge radius results in the fact that the force is shifted in

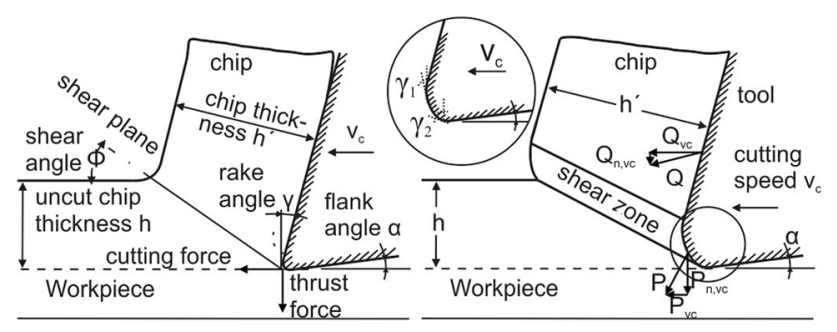

Fig. 4 a Cutting model after Merchant [21]; b rounded cutting edge model after Kim [22] and Albrecht [24] the direction of the generated workpiece surface. This means that a portion of the material to be machined is pushed into the material surface and affects the resulting workpiece integrity. Albrecht [24] distinguishes the force acting on the rake face $\mathrm{Q}$ and the force acting on the rounded cutting edge, the so called plowing force $P$.

Investigations of Ding and Rahman [25] show that the chip formation and as a consequence the cutting forces are influenced by the micro structure and the material properties of the material. Due to the small tool dimensions and the size effect of small ratios of undeformed chip thickness to rounded cutting edges radius, the process behavior in ultra precision and micro machining processes differs from conventional machining:

- the amount of ploughing is much larger, resulting in higher deformation, high friction as well as high temperatures and

- the dimensions of the tool can be in the range of grain sizes or even smaller, hence the micro structure of the work material has direct impact on chip formation.

It is difficult to evaluate the impact of chip formation on economic, environmental and social aspects quantitatively. Generally speaking, the aforementioned properties result into high loads of the tools and hence in tool wear. The impact of the tools is discussed in the following section.

\subsection{Cutting Tool Material}

Ultra precision and micro machining processes allow to produce micrometer, sub-micrometer and nanometer range of surface finish with high repeatability. Thereby, the cutting edge geometry is essential for achieving high surface quality due to the fact that the tool profile is transferred to the workpiece. Generally, diamond, cemented carbide and coated cemented carbide tools are widely used for ultra precision and micro machining processes. Single crystal and poly crystalline diamond tools are largely used for ultra precision cutting [26]. The diamond cutting tools can be broadly classified as natural and synthetic diamond, both having the properties of high wear resistance, heat conductivity, hardness and a low coefficient of friction [27].

A possible problem when using diamond-cutting tools is the chemical affinity of carbon to metals. The affinity leads to oxidization or the transformation of diamond lattice into graphite at high temperatures. This oxidation process and carbon transformation increases the tool wear rate [3]. To enable the application of diamond tools for metal cutting different approaches are investigated like cryogenic cooling [28] or discontinuous cutting with piezo driven tools [29] to reduce the cutting temperature. 
In micro machining, cemented carbide is frequently used as tool material. Tungsten carbide is the most frequently applied carbide for cemented carbide tools. It can withstand high temperatures at the tool-workpiece contact [30]. The quality of the resulting cutting edge depends on the grain size of the cemented carbide [31]. Therefore, ultrafine cemented carbide is commonly used with a grain size of $0.2 \mathrm{~m}$ [17].

Cutting tools for precision manufacturing should satisfy the following requirements [27]:

- Ultra-fine grains to form a sharp cutting edge,

- Homogeneous grain size to avoid tool ruptures at larger grains,

- High Young's modulus, in order to prevent tool drift,

- High hardness, to resist abrasion and high temperatures,

- High compression strength, to avoid plastic deformations at high temperatures,

- High bending strength, to resist tool rupture due to a bending force,

- High fracture toughness, to offer good resistance against crack propagation,

- High resistance against thermal shock due to high temperatures and high temperature gradients.

To extend tool life the cemented carbide tools are coated to reduce tool wear. However, the cutting micro geometry is influenced by the coating. Aramcharoen et al. [32] investigated the influence of different coating systems when micro milling hardened tool steel and showed that chipping of the cutting edge, the flank wear and the burr formation can be reduced by careful selection of the coating. The achievable surface quality both at the beginning and at the end of the process is highly dependent on the selected coating. Reichenbach et al. [33] showed that coating is even possible for ultra small micro end mills ( $D=48 \mu \mathrm{m}$ ).

Wei [34] investigates the influence of a micro textured rake face on the process behavior with a feed rate between $22 \mu \mathrm{m}$ and $44 \mu \mathrm{m}$. The texture was generated by micro abrasive blasting. The results show that the cutting force decreases with textured rake face due to the minimized friction.

\subsection{Workpiece Materials}

Workpiece material properties, like the microstructure and grain orientation, highly affect surface topographical features like surface roughness, plastic side flow, or plastic deformation of workpiece material [35]. Moreover, ductile and brittle materials behave very differently under the same machining conditions. For example, the machining of brittle material tends to initiate micro cracks, which leads to discontinuous chip formation [36]. Copper, aluminum alloy
6061, aluminum bronze (Al-bronze) are machined by single crystal diamond tools [37]. Aluminum alloys are using for the manufacturing of mirrors used as magnetic disks [38].

Titanium is a difficult-to-machine or hard-to-cut material and leads to extremely high cutting temperatures at the cutting zone and low surface qualities. Furthermore, titanium alloys have low thermal conductivity with high thermal capacity, which makes Titanium chemically reactive to all known cutting tool materials and prone to built-up-edge formation (BUE), smearing, chipping, or adhesive wear [39, 40]. Studying and controlling these factors during UPM are important due to sophisticated usage of titanium alloys in medical and dental prostheses due to its high biocompatibility [41].

Several studies reported that UPM induced different degree of microstructural changes and phase decomposition depending on workpiece material. To et al. [42] reported that $\mathrm{Zn}-\mathrm{Al}$ milled surfaces accelerate microstructural changes with increasing the depth of cut. Wang et al. [43] found that UPM process causes cutting induced heating effect on workpieces and results time-temperature-dependent phase precipitation on the workpiece. The theoretical and experimental observation [25] indicated that the cutting temperature has an impact on elastic recovery and surface roughness of workpieces. The after impacts on workpieces are dependent on the hardness and strength properties of materials. Wang et al. [44] worked on raster milled Al6061, copper and on Albronze workpieces, where it has been found that Albronze has the higher effect on surface quality due to its hardness and fast elastic recovery, whereas, copper produced lowest surface roughness.

Another factor, which influence on surface quality in micro machining and ultraprecision manufacturing is burr formation due to the variation of chip thickness, tool sharpness, tool feed mode or workpiece geometry [45]. Several experimental and theoretical analysis [43, 45-47] have shown that larger tool edge radius and ductile workpiece produces larger burr size, whereas, sharper tool, smaller tool edge angle, and bigger edge angle of workpiece produces smaller burr size. Peng et al. [48] studied critical ductile-brittle transition depth of cut for fly cutting and have showed that small feed rates and large negative rake angles causes higher material removal area and produces smoother surfaces.

In the area of ultra precision and micro machining, steel alloys are used to manufacture forming dies for example for optical components [49]. In addition to these commonly used materials, there are also few other commercially available materials in the market like ceramics. Due to their individual properties, like high hardness, strength, ductility, toughness or low thermal conductivity, the machining of these materials can result into short tool life, poor surface quality, poor geometrical accuracy. 
Furthermore, polymers are used in ultra precision and micro machining for example to manufacture microfluidics as lab-on-a-chip platforms for life sciences or chemical analytic applications [50]. The direct milling of such structures on a desktop machine can reduce cost and manufacturing time compared to e.g. lithography [51]. Below the glass transition temperature, the cutting mechanism is mainly brittle. Around the glass transition temperature, the cutting mechanism is ductile. Too high temperature leads to smearing whereby the cutting process is difficult to control [52].

Overall, in ultraprecision manufacturing and in micromachining, more theoretical analysis are required for comprehensive understanding about material swelling and recovery effect, as well as, to have deep understanding regarding the tool mark irregularity, surface cracking or about material separation.

\subsection{Cooling and Lubrication}

Cooling and lubrication systems are necessary to cool down the spindle and peripheral tools and to reduce friction. Use of proper lubricants ensures prolonged product life, reduced cutting temperatures, less formation of built up edges, and less tool wear.

Ultra precision and micro machining necessitates small depths of cut, which, compared to conventional machining processes, result into small cutting forces [48]. The accurate control of flow rate or removal of excessive lubricants after the machining process are challenging for precision manufacturing. Therefore, great attention is to be paid on selecting the proper lubrication or cutting fluids to remove chips and debris during the machining processes [37, 53].

Selecting suitable cutting fluids and proper consumption rates as well as the cutting fluids disposals are challenging for ultra precision and micro machining. Different studies have been reported in the literature to develop different cooling techniques including cryogenic cooling, minimum quantity lubrication, dry and near dry machining, high pressure cooling, air/vapor/gas cooling etc. [54, 55]. Among these dry cutting reduces negative impact on the environment and might increase sustainability from a social, economical, and environmental point of view. The downside of using dry cutting condition compromised surface quality. In order to balance between sustainability and surface quality, minimum quantity lubrication (MQL) is becoming more encouraged to use for UP manufacturing. The impact of different cooling process on cutting tools has shown by Weinert et al. [56]. Figure 5 shows cutting tool edge condition after end milling process using MQL and dry cutting condition respectively and there was clear mark of tool wear for dry cutting condition. Other than MQL, dry/near dry cutting fluid condition, several other approaches have been made to make the process greener. Tai et al. [57] investigated on different oil
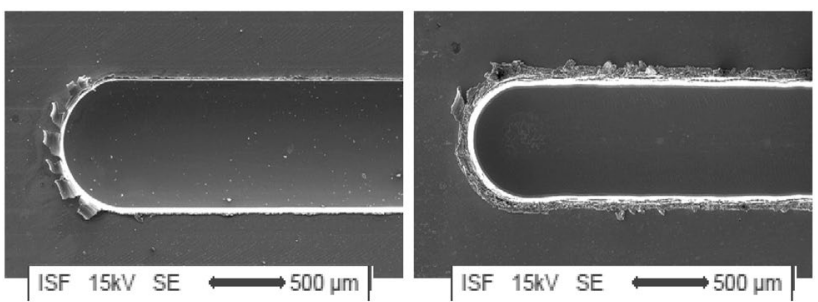

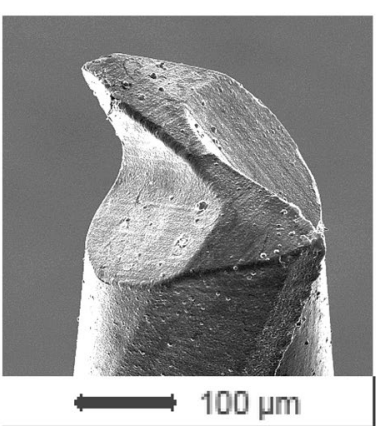

(a) MQL

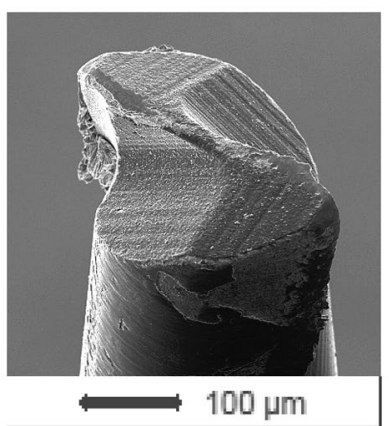

(b) Dry
Fig. 5 Micro-end milling experiments under MQL and Dry (work material: NiTi shape memory alloy, cutting speed: $v_{c}=33 \mathrm{~m} / \mathrm{min}$, depth of cut: $a_{p}=10 \mu \mathrm{m}$, width of cut: $a_{e}=40 \mu \mathrm{m}$, feed: $f_{z}=12 \mu \mathrm{m}$, cemented carbide with TiAlN coating, $\mathrm{d}=400 \mu \mathrm{m}$; Reprinted from Dornfeld et al. [5] and Weinert et al. [56])

based lubrication; Liu et al. [53] developed water vapor as a coolant and lubricant. Das et al. [58] reported nano-particles enhanced cutting fluids (NPCF), which consists of nanometric size $\mathrm{Al}_{2} \mathrm{O}_{3}, \mathrm{CuO}$ ultra-fine particles for efficient convective heat transfer from the cutting zone.

Another aspect of cutting fluids is the health risk. Sometimes cutting fluids favor the growth of microbes, skin contact may potentially cause skin disease, close proximity might cause respiratory problem to the operator due to vaporized nanoparticle inhalation from cutting fluids [52]. The optimum balance between better product quality, economic use, disposal of cutting fluids, and reduced health impact on operators are desirable for choosing cutting fluids for UP manufacturing.

\section{Approaches to Increase Energy Efficiency and Sustainability}

The collection of the necessary data for a complete life cycle assessment is very challenging. Although the energy efficiency is only a part of the whole life cycle assessment, the consideration of the energy efficiency can provide a good overview in those cases where energy has a significant influence on the environmental performance [59]. Aurich et al. [59] developed an approach for abrasive processes in which the manufactured products are classified into three categories: 
- Low embodied energy, high energy usage (Class A)

- High embodied energy, low/no energy usage (Class B)

- Energy generating (Class C)

In this part of the paper, the classification of Aurich et al. [58] will be transferred to ultraprecision and micro machining processes.

Class A products are characterized by the fact that their energy demand in usage substantially exceeds the energy input of the manufacturing process (see Fig. 6). To improve the sustainability of class A products it is necessary to put more energy in the process design. An example for this product class are tribologically loaded components. An increased energy input for such products could be to structure the functional surfaces of the product via micro machining. By means of the micro structure it is possible to reduce friction and wear in the tribological system and as a consequence the energy usage of the product for the whole LC. Examples for such products are tribological stressed parts $[60,61]$ as cylinders or bearings.

Products classified in class B exhibit no or only slight energy demand during their use phase (see Fig. 7). That means that the generated surface has little or no impact on the life time of the product. Due to this the efficiency of Type B products is directly linked to the efficiency of the manufacturing process. An overall increase of the energy efficiency of the product can hence be achieved by improving the efficiency of the process, as for example by reducing the processing time or the tool costs. Typical class B products are consumer products as for example watches and biological products as implants or optical components as for example displays or lenses for cellular phones.

Products of class $\mathrm{C}$ are characterized by the fact that they are involved in energy production during their life cycle (see Fig. 8). An improvement of the efficiency of such products results into a higher energy generation during their use. This higher efficiency can be achieved by a higher effort or energy input in the machining of such products and ultimately can result in a positive energy balance, similar to Class A products.

Examples for such products are engines or bio reactors. An optimized nozzle design of injection pumps of engines e.g. through micro holes could result into a more efficient fuel injection. Microstructures for bio reactors could enhance cell culture production to improve the efficiency.
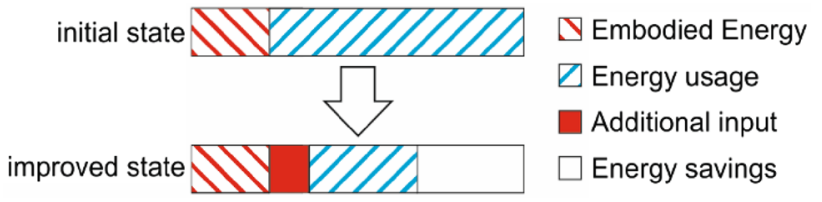

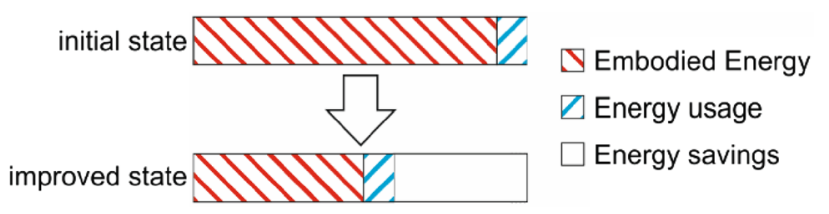

Fig. 7 High embodied energy, low/no energy usage-type B [59]

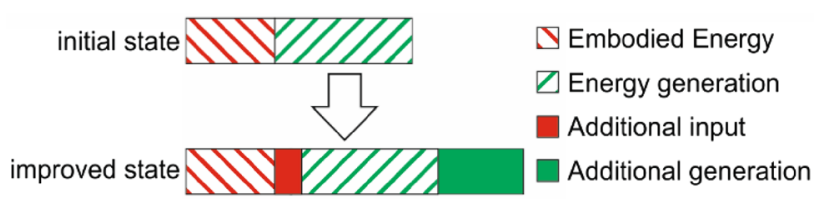

Fig. 8 Energy generation-type C [59]

The three product classes help to decide if the energy expended in the process has to be reduced, is not worth to be reduced or should even be increased to extend the efficiency of the manufactured product. The energy expended in the process can be influenced by several aspects, as outlined in chapter 3 of this paper. That is, improvement in the sustainability of machine tools, e.g. by the development of desktop size machine tools, of the process, e.g. by improved chip formation, of the tools, e.g. by changing tool geometries, by the workpiece, e.g. via heat treatments, or by the lubrication, e.g. by applying nanofluids, can help to increase energy efficiency during machining. To be able to decide which strategy increases sustainability, a complete life cycle inventory of the respective product is advised.

In addition to the named energy aspects, economic aspects become more and more important for parts manufactured via ultra precision or micro machining. Traditional applications, particularly of ultra precision machining, are very expensive parts like e.g. telescope mirrors (Class B products). For such expensive products, the costs of the final finishing through ultra precision machining are not decisive. Or in other words, energy savings for such Class B products increase sustainability in terms of environmental aspects but only marginally in terms of economic aspects. However, the fast development in the area of personal devices in the last decade completely changed this traditional role of ultra precision processes being only a machining process for high-end products. The extremely high demand in numbers of lenses for cameras in smartphones, tablets and laptops at low prices demands for fast and efficient processes. So energy savings in such mass production Class B products also contribute to the economic aspects of sustainability.

Fig. 6 Low embodied energy, high energy usage — type A [59] 


\section{Conclusion and Outlook}

Ultra precision and micro machining processes are key technologies to fulfill the rising demand for micro parts and components. This increase in importance necessitates a careful consideration of the sustainability of those processes.

In this paper, sustainability aspects of the system "Ultra precision and micro machining" were discussed. The decisive aspects were identified and elaborated in detail. Products machined by ultra precision and micro machining were categorized in three different classes. This helps to decide if the energy expended in the process has to be reduced, is not worth to be reduced or should even be extended to increase the efficiency of the manufactured product. The energy expended in turn can be influenced by changing one or more of the decisive aspects outlined in the paper.

The findings in this paper are a first step towards increasing sustainability of ultra precision and micro machining processes. Future work has to closely consider each aspect of the whole system with regard to sustainability. This includes technological, e.g. the advantage of hybrid processes [62] as well as organizational aspects, embodied energy in ultra precision and micro machining process or the influence of the micro chips on the health of the workers.

Acknowledgements This research was partly funded by the German Research Foundation (DFG) within the Collaborative Research Center (CRC) 926 "Microscale Morphology of Component Surfaces" and the International Research Training Group (IRTG) 2057 "Physical Modeling for Virtual Manufacturing Systems and Processes". On behalf of all authors, the corresponding author states that there is no conflict of interest. Figures reprinted with permission from the copyright owners; see references for further information on original source.

Open Access This article is distributed under the terms of the Creative Commons Attribution 4.0 International License (http://creativeco mmons.org/licenses/by/4.0/), which permits unrestricted use, distribution, and reproduction in any medium, provided you give appropriate credit to the original author(s) and the source, provide a link to the Creative Commons license, and indicate if changes were made.

\section{References}

1. Dornfeld, D. (2011). Leveraging manufacturing for sustainable future. In Proceedings of the 18th CIRP international conference on life cycle engineering (pp. 17-21).

2. Dornfeld, D. (2010). Sustainable manufacturing-Greening processes, systems and products. In Proceedings of the international chemnitz manufacturing colloquium (pp. 99-113).

3. Dornfeld, D. (2007). Technology wedges for implementing green manufacturing. Transactions of NAMRI/SME, 35, 193-200.

4. Kang, H.-J., \& Ahn, S.-H. (2007). Fabrication and characterization of microparts by mechanical micromachining: Precision and cost estimation. Proceedings of the Institution of Mechanical Engineers, Part B: Journal of Engineering Manufacture, 221(2), 231-240.
5. Dornfeld, D., Min, S., \& Takeuchi, Y. (2006). Recent advances in mechanical micro machining. CIRP Annals Manufacturing Technology, 55(2), 745-768.

6. Yoon, H.-S., Lee, J.-Y., Kim, H.-S., Kim, M.-S., Kim, E.-S., Shin, Y.-J., et al. (2014). A comparison of energy consumption in bulk forming, subtractive, and additive processes: Review and case study. International Journal of Precision Engineering and Manufacturing-Green Technology, 1(3), 261-279.

7. Mativenga, P. (2014). Micro machining. In CIRP encyclopedia of production engineering (pp. 873-877). https://doi. org/10.1007/978-3-642-20617-7.

8. Brinksmeier, E. (2014). Ultra precision machining. In CIRP encyclopedia of production engineering (pp. 1277-1280). https://doi. org/10.1007/978-3-642-20617-7.

9. Brinksmeier, E., Oltmann, R., Brandao, C., Meier, A., Böhmermann, F. (2013). Potenziale der Mikrofertigung-Neue Wege der Bearbeitung und innovative Maschinenkonzepte. Industrie Management, 29(2).

10. Ikawa, N., Donaidson, R. R., Komunduri, R., Konig, W., Mckeown, P. A., Moriwaki, T., et al. (1991). Ultra precision metal cutting - The past, the present and the future. CIRP Annals-Manufacturing Technology, 40(2), 587-594.

11. Ge, Y. F., Xu, J. H., Yang, H., Luo, S. B., \& Fu, Y. C. (2008). Workpiece surface quality when ultra precision turning if $\mathrm{SiCp} /$ Al composites. Journal of Materials Processing Technology, $203,166-175$.

12. Solon, T. (2012). Fundamentals of ultraprecision machining. Machine Design.com, No. 5.

13. Vollersten, F., Biermann, D., Hansen, H. N., Jawahir, I. S., \& Kuzman, K. (2009). Size effects in manufacturing of metallic components. CIRP Annals-Manufacturing Technology, 58, 566-587.

14. ISO 14040. (2006). Life cycle assessment-Principles and framework.

15. The World Commission on Environment and Development, Our Common Future (1987).

16. Linke, B., \& Overcash, M. (2012). Life cycle analysis of grinding. In Proceedings of the 19th CIRP conference on life cycle engineering (pp. 293-298).

17. Grimske, S., Kong, N., Röhling, B., \& Wulfsberg, J. P. (2014). Square foot manufacturing-A modular and mutable desktop machine tool system. Mechanics Based Design of Structures and Machines: An International Journal, 32(3), 386-397.

18. Aurich, J. C., Reichenbach, I. G., \& Schüler, G. M. (2012). Manufacture and application of ultra-small micro end mills. CIRP Annals-Manufacturing Technology, 61, 83-86.

19. Lucca, D. A., Rhorer, R. L., \& Komanduri, R. (1991). Energy dissipation in the ultraprecision machining of copper. CIRP Annals-Manufacturing Technology, 40(1), 69-72.

20. Moriwaki, T., \& Shamoto, E. (1991). Ultra precision diamond turning of stainless steel by applying ultrasonic vibration. CIRP Annals-Manufacturing Technology, 40(1), 559-562.

21. Merchant, M. E. (1945). Mechanics of the metal cutting process. II. Plasticity conditions in orthogonal cutting. Journal of Applied Physics, 16, 318-324.

22. Kim, J.-D., \& Kim, D. S. (1995). Theoretical analysis of microcutting characteristics in machining. Journal of Materials Processing Technology, 49, 387-398.

23. Balogun, V. A., \& Mativenga, P. T. (2014). Impact of undeformed chip thickness on specific energy in mechanical machining processes. Journal of Cleaner Production, 69, 260-268.

24. Albrecht, P. (1960). New developments in the theory of the metalcutting process-Part I. The ploughing process in metal cutting. Transactions of the ASME, 82, 348-358. 
25. Ding, X., \& Rahman, M. (2012). A study of the performance of cutting polycrystalline $\mathrm{Al} 6061 \mathrm{~T} 6$ with single crystalline diamond micro-tools. Precision Engineering, 36, 593-603.

26. Cheng, K., \& Huo, D. (2013). Micro-cutting-Fundamentals and applications. New York: Wiley.

27. Löhe, D., \& Haußelt, J. (2005). Microengineering of metals and ceramics. Part I: Design, tooling, and injection molding. New York: Wiley-VCH.

28. Evans, C. (1991). Cryogenic diamond turning of stainless steel. CIRP Annals-Manufacturing Technology, 40(1), 571-575.

29. Brinksmeier, E., \& Gläbe, R. (1999). Elliptical vibration cutting of steel with diamond tools. In Proceedings of ASPE fourteenth annual meeting of the ASPE (pp. 163-166).

30. Byrne, G., Dornfeld, D., \& Denkena, B. (2003). Advancing cutting technology. CIRP Annals-Manufacturing Technology, 52(2), 483-507.

31. Schaller, T., Bohn, L., Mayer, J., \& Schubert, K. (1999). Microstructure grooves with a width of less than $50 \mathrm{~mm}$ cut with ground hard metal micro end mills. Precision Engineering, 23, 229-235.

32. Aramcharoen, A., Mativenga, P. T., Yang, S., Cooke, K. E., \& Teer, D. G. (2008). Evaluation and selection of hard coatings for micro milling of hardened tool steel. International Journal of Machine Tools and Manufacture, 48(14), S1578-S1584.

33. Reichenbach, I. G., Bohley, M., \& Aurich, J. C. (2015). TiAlN coated ultra-small micro end mills. In Proceedings of the 15th international conference of the EUSPEN (pp. S. 321-S. 322).

34. Wei, Y., Kim, M.-R., Lee, D.-W., Park, C., \& Park, S. (2017). Effect of micro textured sapphire tool regarding cutting forces in turning operations. International Journal of Precision Engineering and Manufacturing Green Technology, 4(2), 141-147.

35. Jasinevicius, R. G., de Campos, G. P., Montanari, L., Tsukamoto, R., Garcia, J. P., Camargo, R., et al. (2003). Influence of the mechanical and metallurgical state of an $\mathrm{Al}-\mathrm{Mg}$ alloy on the surface integrity in ultra precision machining. Journal of the Brazilian Society of Mechanical Sciences, 25(3), 222-228.

36. Jackson, M. J. (2006). Microfabrication and nanomanufacturing. London: Taylor \& Francis.

37. Wang, S. J., To, S., \& Cheung, C. F. (2013). An investigation into material-induced surface roughness in ultra precision milling. The International Journal of Advanced Manufacturing Technology, 68, 607-616.

38. Sugano, T., Takeuchi, K., Goto, T., \& Yoshida, Y. (1987). Diamond turning of an aluminium alloy for mirror. CIRP AnnalsManufacturing Technology, 36(1), 17-20.

39. Shokrani, A., Dhokia, V., \& Newman, S. T. (2012). Environmentally conscious machining of difficult-to-machine materials with regard to cutting fluids. International Journal of Machine Tools and Manufacture, 57, 83-101.

40. Abele, E., \& Frohlich, B. (2008). High speed milling of titanium alloys. Advances in Production Engineering and Management, 3(3), 131-140.

41. Santis, R., Gloria, A., Russo, T., D’Amora, U., Varriale, A., Veltri, M., et al. (2014). Reverse engineering of mandible and prosthetic frame work: Effect of titanium implants in conjunction with titanium milled full arch bridge prostheses on the biomechanics of the mandible. Journal of Biomechanics, 47, 3825-3829.

42. To, S., Zhu, Y. H., \& Lee, W. B. (2008). Microstructural changes at the ultra-precision raster milled surface of $\mathrm{Zn}-\mathrm{Al}$ based alloy. Materials Transactions, 49(4), 698-703.

43. Wang, S., To, S., Chan, C. Y., Cheung, C. F., \& Lee, W. B. (2010). A study of the cutting-induced heating effect on the machined surface in ultra-precision raster milling of $6061 \mathrm{Al}$ alloy. The International Journal of Advanced Manufacturing Technology, 51(1), 69-78.
44. Wang, S. J., To, S., \& Cheung, C. F. (2012). Effect of workpiece material on surface roughness in ultraprecision raster milling. Materials and Manufacturing Processes, 27(10), 1022-1028.

45. Zhang, S. J., To, S., Zhu, Z. W., \& Zhang, G. Q. (2016). A review of fly cutting applied to surface generation in ultra-precision machining. International Journal of Machine Tools and Manufacture, 103, 13-27.

46. Fang, F. Z., \& Liu, Y. C. (2004). On minimum exit-burr in micro cutting. Journal of Micromechanics and Microengineering, 14(7), 984.

47. Fang, F. Z., Xiong, Z., \& Hu, X. T. (2004). Ultra-precision machining of reflector array for laser diode beam shaping. Optoelectronics Letters, 3(2), 141-143.

48. Peng, Y., Jiang, T., \& Ehmann, K. F. (2014). Research on singlepoint diamond fly-grooving of brittle materials. The International Journal of Advanced Manufacturing Technology, 75(9), 1577-1586.

49. Brinksmeier, E., Gläbe, R., \& Osmer, J. (2006). Ultra-Precision diamond cutting of steel molds. CIRP Annals-Manufacturing Technology, 55(1), 551-554.

50. Reichenbach, I. G., \& Aurich, J. C. (2013). Direct machining of micro-structures in polymethyl methacrylate (PMMA) with single-edge micro end mills with diameter $20 \mu \mathrm{m}$. In Proceedings of the 13th international conference of the EUSPEN (pp. S. 35-S. $38)$.

51. Jáuregui, A. L., Siller, H. R., Rodríguez, C. A., \& Elías-Zúñiga, A. (2010). Evaluation of micromechanical manufacturing processes for microfluidic devices. The International Journal of Advanced Manufacturing Technology, 48(9-12), 963-972.

52. Carr, J. W., \& Feger, C. (1993). Ultraprecision machining of polymers. Precision Engineering, 15(4), 221-237.

53. Liu, J., Han, R., \& Sun, Y. (2005). Research on experiments and action mechanism with water vapor as coolant and lubricant in Green cutting. International Journal of Machine Tools and Manufacture, 45(6), 687-694.

54. Chan, C. Y., Lee, W. B., \& Wang, H. (2013). Enhancement of surface finish using water-miscible nano-cutting fluid in ultraprecision turning. International Journal of Machine Tools and Manufacture, 73, 62-70.

55. Sharma, V. S., Dogra, M., \& Suri, N. M. (2009). Cooling techniques for improved productivity in turning. International Journal of Machine Tools and Manufacture, 49(6), 435-453.

56. Weinert, K., Kahnis, P., Petzoldt, V., \& Peters, C. (2005). Micromilling of steel and niti SMA. In 55th CIRP general assembly, $S T C-C$ section meeting presentation file.

57. Tai, B. L., Dasch, J. M., \& Shih, A. J. (2011). Evaluation and comparison of lubricant properties in minimum quantity lubrication machining. Machining Science and Technology, 15(4), 376-391.

58. Das, S. K., Putra, N., Thiesen, P., \& Roetzel, W. (2003). Temperature dependence of thermal conductivity enhancement for nanofluids. Journal of Heat Transfer, 125(4), 567-574.

59. Aurich, J. C., Linke, B., Hauschild, M., Carrella, M., \& Kirsch, B. (2013). Sustainability of abrasive processes. CIRP AnnalsManufacturing Technology, 62, 653-672.

60. Andersson, P., Koskinen, J., Varjus, S., Gerbig, Y., Häfke, H., Georgiou, S., et al. (2007). Microlubrication effect by laser-textured steel surfaces. Wear, 262, 369-379.

61. Zhou, R., Cao, J., Wang, Q. J., Meng, F., Zimowski, K., \& Xia, Z. C. (2011). Effect of EDT surface texturing on tribological behavior of aluminum sheet. Journal of Materials Processing Technology, 211(10), 1643-1649.

62. Chu, W.-S., Kim, C.-S., Lee, H.-T., Choi, J.-O., Park, J. I., Song, J.-H., et al. (2014). Hybride manufacturing in micro/nano scale: A review. International Journal of Precision Engineering and Manufacturing-Green Technology, 1(1), 75-92. 
Publisher's Note Springer Nature remains neutral with regard to jurisdictional claims in published maps and institutional affiliations.

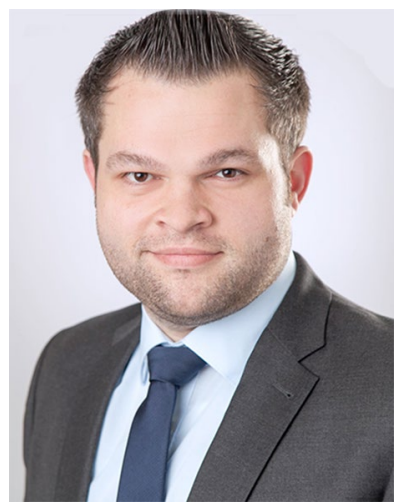

Frank Schneider is Research Engineer at Chair for Manufacturing Technology and Production Systems, Technische Universität Kaiserslautern, Germany. His research interests include ultra precision and micro-machining, machining of high-performance materials and sustainability.

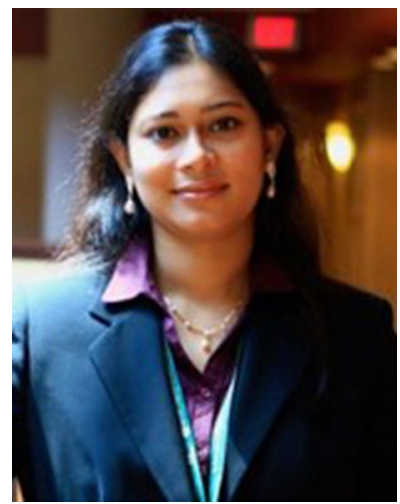

Jayanti Das is a PhD student at Manufacturing and Sustainable Technologies Research Laboratory, University of California, Davis, USA. Her research interests include sustainability and surface engineering.

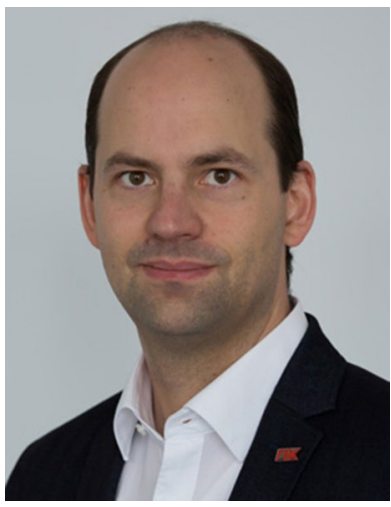

Benjamin Kirsch is Chief Engineering Chair for Manufacturing Technology and Production Systems, Technische Universität Kaiserslautern, Germany. His research interests include ultraprecision and micro-machining and the development of machine tools and tools in this area, as well as conventional machining.

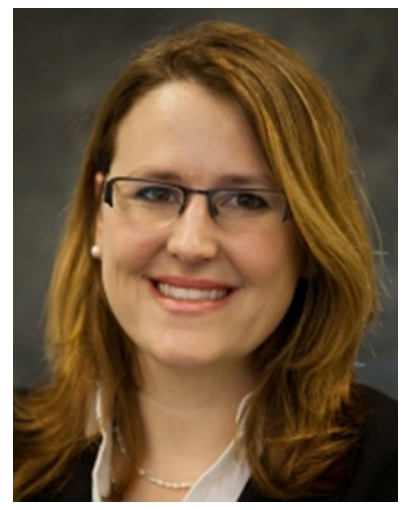

Barbara Linke is Associate Professor for Manufacturing and Sustainable Technologies, University of California, Davis, USA. Her research interests include manufacturing technologies, sustainable and energyefficient manufacturing processes and surface engineering.

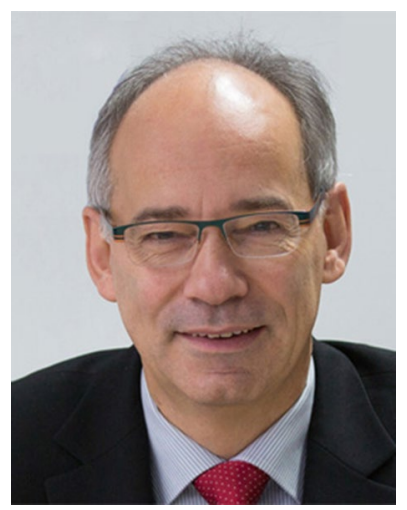

Jan C. Aurich is Professor for Manufacturing Technology and Production Systems, Technische Universität Kaiserslautern, Germany. His research interests include ultra-precision and micro-machining and the development of machine tools and tools in this area, as well as conventional machining. 